\title{
Vitrification alters rabbit foetal placenta at transcriptomic and proteomic level
}

\author{
M D Saenz-de-Juano, F Marco-Jimenez, B Schmaltz-Panneau, E Jimenez-Trigos, \\ M P Viudes-de-Castro, D S Peñaranda, L Jouneau ${ }^{1}$, J Lecardonnel ${ }^{2}$, R Lavara, \\ C Naturil-Alfonso, $V$ Duranthon ${ }^{1}$ and J S Vicente
}

Laboratorio de Biotecnología de la Reproducción, Instituto de Ciencia y Tecnología Animal, Universidad Politécnica de Valencia, C/Camino de Vera s/n, 46022 Valencia, Spain, ${ }^{1}$ INRA, UMR 1198 Biologie du Développement et Reproduction, F-78350 Jouy en Josas, France and ${ }^{2}$ INRA, UMR 1313 Génétique Animale et Biologie Intégrative, CRB GADIE, F-78350 Jouy en Josas, France

Correspondence should be addressed to J S Vicente; Email: jvicent@dca.upv.es

\begin{abstract}
Although numerous studies have demonstrated that cryopreservation alters gene expression, less is known about those embryos that implanted successfully and continued in gestation. To raise the question of the neutrality of this technique, we examine the effects of vitrification through gestation in rabbit before and after the implantation. We monitored the distribution of losses of 569 vitrified morulae, observing that embryos which reach the last pre-implantatory stage are able to implant. However, we found that not all implanted embryos had the ability to continue with their gestation. The results reveal that vitrification decreased foetus and maternal placenta weights at mid-gestation, but led to a higher offspring birth weight. A novel finding is that while no differences in gene expression were detected in pre-implantatory embryos at day 6, vitrification affects a gene and protein expression in the placenta at day 14. Our results for first time reveal strong evidence of modifications in implanted embryos subjected to vitrification, suggesting that the crucial step that vitrified embryos must overcome is the placenta formation. On the basis of these findings, our work leaves the question open as to whether the effects we observed that cause vitrification during foetal development could give rise to some type of physiological or metabolic alteration in adulthood.

Reproduction (2014) 147 789-801
\end{abstract}

\section{Introduction}

Cryopreservation of embryos is considered an important tool in human-assisted reproduction and embryo storage. As it has been shown during the last 20 years, cryopreservation can be harmful to some embryos but is not considered to affect survivors, for which it is regarded as neutral. However, it has been postulated that apart from short-term effects on conceptuses, embryo cryopreservation can have long-term consequences manifesting in adults (Auroux et al. 2004). It seems that the same embryo plasticity which allows embryos to survive and develop under suboptimal conditions could involve changes in the programming events that could determine the set point of physiological and metabolic disorders that carry into adulthood.

Vitrification was introduced in 1985 as a simple and cheap way to cryopreserve mammalian embryos in the absence of ice as reported by Rall \& Fahy (1985). Since then, vitrification is replacing slow freezing as the most popular method for oocyte and embryo cryopreservation
(Desai et al. 2013). However, considerable effort is being made to decrease the toxicity of cryoprotectants, by applying less toxic and more permeable chemicals, decreasing its concentration or increasing the cooling rate, and all that with the development of new carriers (Saragusty \& Arav 2011, Arav 2014).

Previous studies have demonstrated that vitrification procedure influences gene expression and epigenetic patterns of mammalian pre-implantatory embryos (Mamo et al. 2006, Wang et al. 2010, Aksu et al. 2012, Zhao et al. 2012), but none of them studied what happen to those embryos that implant and follow with the gestation, despite it has been detected as problems in the formation of the placenta and foetal losses in the second part of gestation (Mocé et al. 2010, MarcoJiménez et al. 2013, Vicente et al. 2013). Moreover, there is a current death of knowledge of alterations induced by vitrification at proteomic level.

The aim of our study was the evaluation of modifications induced by vitrification in pre-implantatory and implanted embryos that could origin foetal losses or 
introduce changes in the programming events that could lead to physiological and metabolic disorders developed in adulthood.

\section{Materials and methods}

Unless stated otherwise, all chemicals in this study were purchased from Sigma-Aldrich Química S.A.

\section{Animals}

Rabbit does used as donors and recipients belonging to the New Zealand White line from the Instituto de Ciencia y Tecnología Animal at the Universidad Politécnica de Valencia. All animals were handled according to the principles of animal care published by Spanish Royal Decree 53/2013 (BOE, 2013; BOE is the official Spanish State Gazette).

\section{Experimental design}

Figure 1 illustrates the experimental design. Embryos were recovered at day 3 of development, vitrified or not, and then transferred to recipient does. At day 6 , some of the recipients were slaughtered and late blastocyst embryos were recovered to proceed with the transcriptomic analysis. At day 14, another part of the recipients were also slaughtered and the foetal development was evaluated by weighting the foetus, the foetal placenta, and the maternal placenta. Moreover, transcriptomic and proteomic analyses of the foetal placentas were carried

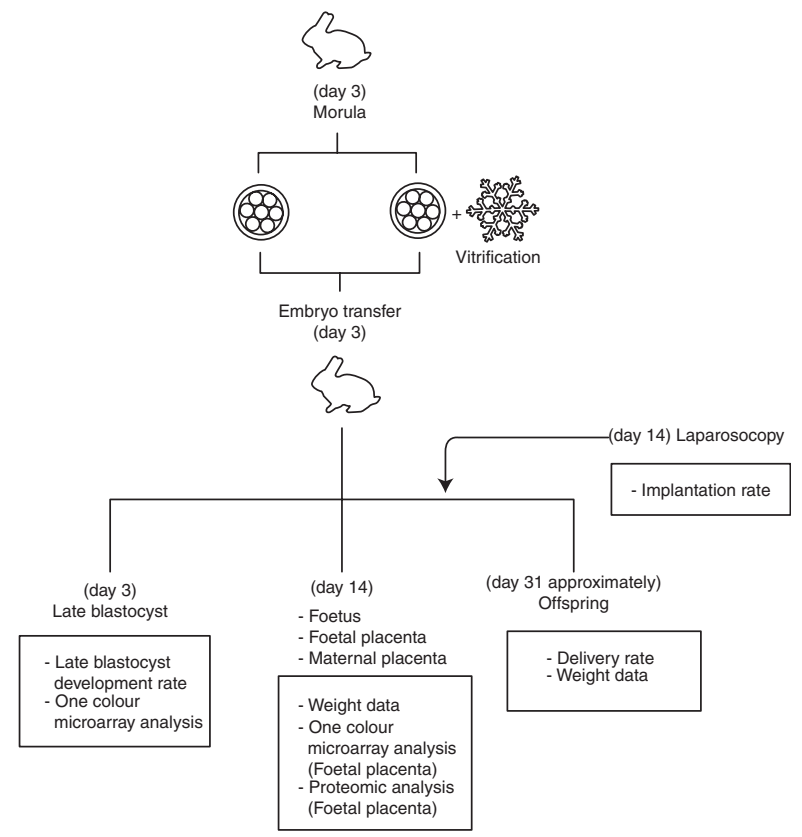

Figure 1 Experimental design. Embryos were recovered at day 3 of development, vitrified or not, and then transferred to recipient does. Part of the recipients was slaughtered at day 6 or day 14 in order to evaluate pre-implantatory development or foetal development. The offspring from the rest of females were examined at the end of gestation. out. From the rest of females, birth rates were examined at the end of gestation, and weights of new borns were annotated at the same birthday.

\section{Embryo collection}

Donor does were artificially inseminated with pooled sperm from fertile males and slaughtered at $72 \mathrm{~h}$ post-insemination. Embryos were recovered by perfusion of each oviduct and uterine horn with $10 \mathrm{ml}$ pre-warmed Dulbecco PBS supplemented with $0.2 \%$ of BSA. Morphologically, normal embryos (with homogenous blastomers, intact mucin coat and zona pellucid) were distributed in pools of 15 embryos for fresh transfer or vitrification.

\section{Vitrification and warming procedure}

Embryos were vitrified using the methodology described by Vicente et al. (1999). Briefly, the vitrification procedure was carried out in two steps at $20{ }^{\circ} \mathrm{C}$. In the first step, embryos were placed for $2 \mathrm{~min}$ in a vitrification solution consisting of $12.5 \%$ DMSO and $12.5 \%$ ethylene glycol (EG) in DPBS supplemented with $0.2 \%$ of BSA. In the second step, embryos were suspended for $30 \mathrm{~s}$ in a solution of 20\% DMSO and 20\% EG in DPBS supplemented with $0.2 \%$ of BSA. Then, embryos suspended in vitrification medium were loaded into $0.125 \mathrm{ml}$ plastic straws (French ministraw, IMV, L'Aigle, France) and two sections of DPBS were added at either end of each straw, separated by air bubbles. Finally, straws were sealed and plunged directly into liquid nitrogen. Warming was done by horizontally placing the straw $10 \mathrm{~cm}$ from liquid nitrogen for 20-30 s and when the crystallisation process began, the straws were immersed in a water bath at $20{ }^{\circ} \mathrm{C}$ for $10-15 \mathrm{~s}$. The vitrification medium was removed while loading the embryos into a solution containing DPBS and $0.33 \mathrm{M}$ sucrose for $5 \mathrm{~min}$, followed by one bath in a solution of DPBS for another $5 \mathrm{~min}$. Only non-damaged embryos, with intact mucin coat and zona pellucid, were considered to follow with the transfer (94.4\%).

\section{Embryo transfer}

A total of 569 vitrified and 369 morphologically fresh normal embryos were transferred into the oviducts of 70 recipient does (13-14 embryos per recipient) by laparoscopy, following the procedure described by Besenfelder \& Brem (1993). Ovulation was induced in the recipient does with an i.m. dose of $1 \mathrm{mg}$ Buserelin Acetate (Suprefact, Hoechst Marion Roussel S.A, Madrid, Spain) 68-72 $\mathrm{h}$ before transfer. To sedate the does during laparoscopy, anaesthesia was administered by an i.m. injection of $16 \mathrm{mg}$ xylazine (Bayer AG), 5 min later followed by an i.v. injection of 16-20 mg ketamine hydrochloride (Imalgène, Merial SA, Lyon, France). During laparoscopy, $12 \mathrm{mg}$ morphine hydrochloride (Morfina, B. Braun, Barcelona, Spain) was administered intramuscularly. After surgery, does were treated with antibiotics (200 000 IU procaine penicillin and $250 \mathrm{mg}$ streptomycin, Duphapen Strep, Pfizer, S.L.) and buprenorphine hydrochloride $(0.08 \mathrm{mg}$ every $12 \mathrm{~h}$ for 3 days, Buprex, Esteve, Barcelona, Spain). 


\section{Embryonic development, implantation and delivery rates}

From 70 recipient does, a total of 44 were slaughtered at two time of gestation: 6 and 14 days of development. To evaluate the late blastocyst development rate and mRNA profile, 26 recipient does (16 recipient does transferred with vitrified embryos and ten with fresh embryos) were slaughtered $72 \mathrm{~h}$ after transfer and 6-day-old embryos were recovered by perfusion of each uterine horn with $10 \mathrm{ml}$ DPBS supplemented with $0.2 \%$ of BSA. To analyse the effects of vitrification on the foetal placenta at day 14 of development, 18 receptive does (ten recipient does transferred with vitrified embryos and eight with fresh embryos) were slaughtered and samples for transcriptomic and proteomic analyses were recovered. Moreover, to evaluate morphological alterations in the foetal development for each foetus, the data of its weight and foetal or maternal placenta weights were collected. In the rest of 26 recipients does (16 recipients does transferred with vitrified embryos and ten with fresh embryos), foetal survival were studied till the end of gestation. Implantation (number of implanted embryos at day 14 from total embryos transferred) was assessed by laparoscopy. Birth rates were calculated as kits born/total embryos transferred, and born foetus were weighed the same delivery day.

\section{RNA extraction}

PolyA RNA was extracted of pools consisting of 6-8 embryos using Dynabeads kit, following the manufacturer's instructions. In the case of foetal placental, pools consisting of portions of three different foetuses were used for each RNA extraction. Total RNA was isolated using traditional phenol/chloroform extraction with Trizol reagent (Invitrogen S.A.). RNA concentration, quality and integrity were evaluated by Bioanalyzer 2100 (Agilent Technologies, Madrid, Spain). Nine independent pools of 6-dayold embryos and 14-day-old foetal placenta tissues were produced for each experimental group (control and vitrified).

\section{Amplification and sample labelling}

Four samples of each group were used as biological replicates for the microarray analysis: 5 ng PolyA RNA from 6-day-old embryos and 200 ng total RNA from foetal placenta tissue were amplified and labelled with cyanine 3 (Cy3) dye using a QuickAmp labelling kit (Agilent Technologies). Excess dye was removed with QIAquick PCR purification kit (Qiagen), and dye incorporation and concentration were determined using the microarray setting on the Nanodrop 2000 (Thermo Scientific, Madrid, Spain) and Bioanalyzer 2100 (Agilent Technologies).

\section{Hybridisation, washing and scanning of microarrays}

Equal amounts of Cy3 labelled samples (600 ng) were mixed with blocking agent and fragmentation buffer, and then $24 \mu \mathrm{l}$ of the mixture was hybridised into the rabbit oligonucleotide array GPL16482, Agilent Technologies. After $17 \mathrm{~h}$ at $65^{\circ} \mathrm{C}$, hybridised slides were washed and scanned.

\section{Microarray data analysis}

The raw data intensity files were read into $\mathrm{R}$ (www.r-project. org). Identification of differentially expressed genes from blastocyst and foetal placentas was achieved using Limma package. $P$ values obtained by this analysis were adjusted for multiple testing using the Benjamini and Hochberg false discovery rate method. Probes with $P$ value $<0.05$ were considered significant. The list of differentially expressed genes was then submitted to DAVID database and to Ingenuity Pathways Analysis software (IPA) (Ingenuity, Inc., Redwood City, CA, USA, http://www.ingenuity.com), in order to asses functional annotation of the genes and to provide an estimation of the signalling and metabolic pathways, molecular networks and biological processes that were most significantly perturbed in the vitrification condition.

\section{Q-RT-PCR}

In the rest of 26 recipient does (16 recipients does transferred with vitrified embryos and 10 with fresh embryos) the offspring were examined at the end of gestation. As stated before, pools consisting of 6-8 embryos and three portions of foetal placentas were used for RNA extraction. Genes were selected according to the fold-change, $P$ value and their importance in embryo and foetal development. To prevent DNA contamination, one deoxyribonuclease treatment step (gDNA Wipeout Buffer, Qiagen Iberia SL) was carried out from PolyA RNA (5 ng) and total RNA (1000 ng). Then, RT was carried out using Reverse Transcriptase QuantiTect kit (Qiagen Iberia SL) according to the manufacturer's instructions. Real-time PCRs were carried out with an Applied Biosystems 7500 (Applied Biosystems). Each PCR was carried out from $5 \mu$ diluted 1:10 cDNA template, $250 \mathrm{nM}$ of forward and reverse specific primers (Table 1) and $10 \mu \mathrm{l}$ of PowerSYBR Green PCR Master Mix (Fermentas GMBH, Madrid, Spain) in a final volume of $20 \mu \mathrm{l}$. The PCR protocol included an initial step of $50{ }^{\circ} \mathrm{C}(2 \mathrm{~min})$, followed by $95^{\circ} \mathrm{C}$ (10 min) and 42 cycles of $95^{\circ} \mathrm{C}(15 \mathrm{~s})$ and $60{ }^{\circ} \mathrm{C}(30 \mathrm{~s})$. After real-time PCR, a melting curve analysis was carried out by slowly increasing the temperature from 65 to $95^{\circ} \mathrm{C}$, with continuous recording of changes in fluorescent emission intensity. The amplification products were confirmed by SYBRGreen-stained $2 \%$ agarose gel electrophoresis in $1 \times$ Bionic buffer. Serial dilutions of cDNA pool made from several samples were done to assess PCR efficiency. A $\Delta \Delta C$ t method adjusted for PCR efficiency was used, employing the geometric average of $\mathrm{H} 2 \mathrm{~A}$ histone family member $\mathrm{Z}(H 2 A F Z)$ and glyceraldehyde-3-phosphate dehydrogenase $(G A P D H)$ as housekeeping normalisation factor (Weltzien et al. 2005). Relative expression of cDNA pool from various samples was used as the calibrator to normalise all samples within one Q-RT-PCR run or between several runs.

\section{Protein extraction and quantification}

Proteins were extracted from foetal placental tissue by sonication in $500 \mu \mathrm{l}$ RIPA buffer combined with an antiprotease enzyme. Then, the samples were incubated on ice for $20 \mathrm{~min}$ and centrifuged at maximum speed for $20 \mathrm{~min}$ more. 


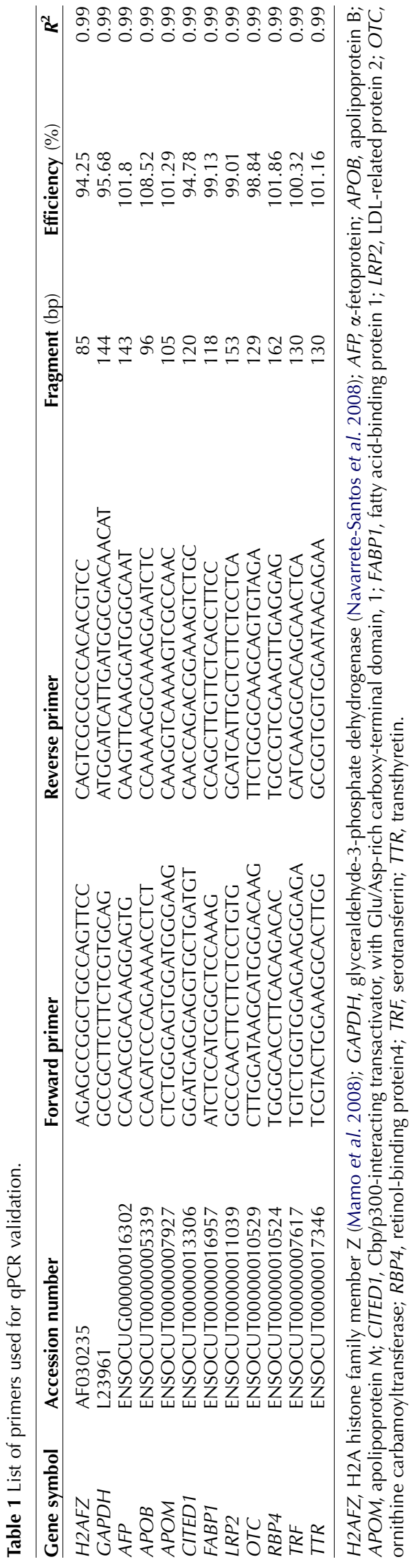

Supernatant were collected and total protein was quantified using BCA Protein Assay Kit (Thermo Scientific) using BSA as standard. To perform 2D DIGE analysis, two pools were made up with eight samples for each experimental group, vitrified and control.

\section{Fluorescent protein labelling and 2D DIGE analysis}

Protein labelling and 2D DIGE analyses were carried out as previously described (Muñoz-Fambuena et al. 2013). A total of $50 \mu \mathrm{g}$ protein of control and vitrified pools were labelled individually with the dyes Cy 3 and Cy5 respectively. The internal standard was created by pooling an aliquot of both biological samples analysed in the experiment and labelled with Cy2. Strips of $24 \mathrm{~cm}$ long with an immobilised $\mathrm{pH}$ gradient from 3 to 11 were used for the first dimension, and the second dimension was performed using a $12.5 \%$ SDS-PAGE gel. After electrophoresis, CyDye-labelled proteins were visualised by fluorescence scanning using a Typhoon Trio scanner (GE Healthcare, Valencia, Spain) with the wavelengths corresponding to each CyDye and the scanned pictures were then directly transferred to the ImageQuant V5.2 software package (GE Healthcare). Image gel analysis was carried out using the DeCyder 2D Software V6.5 (GE Healthcare).

\section{Protein identification}

For picking 27 spots of interest, preparative gels were first stained with Silver Staining Kit Protein (GE Healthcare). Then, proteins were manually excised from gels and washed. The samples were digested with sequencing grade trypsin (Promega) as previously described by Shevchenko et al. (1996) and subjected to liquid chromatography and tandem mass spectrometry (LC/MS/MS). A volume of $5 \mu \mathrm{l}$ of each sample was loaded onto a trap column (NanoLC Column, $3 \mu \mathrm{m} \mathrm{C18-CL,}$ $75 \mu \mathrm{m} \times 15 \mathrm{~cm}$; Eksigen, Madrid, Spain) and desalted with $0.1 \%$ TFA at $2 \mu \mathrm{l} / \mathrm{min}$ during $10 \mathrm{~min}$. Then, peptides were then loaded onto an analytical column (LC Column, $3 \mu \mathrm{m}$ C18-CL, $75 \mu \mathrm{m} \times 25 \mathrm{~cm}$, Eksigen) equilibrated in $5 \%$ acetonitrile and $0.1 \%$ formic acid (FA). Elution was carried out with a linear gradient of 5 a $35 \% \mathrm{~B}$ in A for $30 \mathrm{~min}$. (A: $0.1 \% \mathrm{FA}$; B: ACN, $0.1 \% \mathrm{FA}$ ) at a flow rate of $300 \mathrm{nl} / \mathrm{min}$. Peptides were analysed in a mass spectrometer nanoESI-qQTOF (5600 TripleTOF, ABSCIEX, Madrid, Spain). The tripleTOF was operated in an information-dependent acquisition mode, in which a $0.25 \mathrm{~s}$ TOF MS scan from 350 to $1250 \mathrm{~m} / \mathrm{z}$ was performed, followed by 0.05 -s product ion scans from 100 to $1500 \mathrm{~m} / z$ on the 50 most intense $2-5$ charged ions. A base peak chromatogram was generated for every sample.

Then, MASCOT software (Matrix Science, London, UK) was used to search those spectra on Swiss-Prot and NCBI nr databases. Searches were done with tryptic specificity, allowing one missed cleavage and a tolerance on the mass measurement of 100 or 75 ppm in MS mode and 0.6 Da for MS/MS ions. Carbamidomethylation of Cys was used as a fixed modification and oxidation of Met and deamidation of Asn and GIn as variable modifications. Proteins showing higher score than homology or significance threshold were identified with confidence $\geq 95 \%$. 
Finally, the identified protein sequences were uploaded to BLAST2GO version 2.6.4 software, and functional annotation was performed using BLASTP against NCBI nr-with default parameters.

\section{Statistical analysis}

Effect of vitrification on survival rates at day 6, day 14 , delivery and post-implantation loss rates were analysed using a $\chi^{2}$ test with Yates' correction. Foetus, foetal and maternal placenta, and new-born weights measurements were analysed using a general linear model (GLM). For the new-born analysis, the covariate 'number of young rabbit born in each delivery' was included. Data of relative mRNA abundance were normalised by a Napierian logarithm transformation and evaluated using a GLM too. Analyses were performed with SPSS 16.0 software package (SPSS Inc., 2002). Values were considered statistically different at $P$ value $<0.05$. Results were reported as least square means with S.E.M.

\section{Results}

\section{Vitrification causes detrimental effects on rabbit embryo and foetal development with two major peaks of losses: one before and the other after the implantation}

To investigate the effect of vitrification procedure on distribution losses during gestation, the late blastocyst development, implantation and delivery rates were examined. As shown in Fig. 2A, significant differences were observed between survival rates of fresh control and vitrified embryos at day 6 ( 82.7 vs $63.1 \%, P<0.05$ ), day $14(81.7$ vs $66.4 \%, P<0.05)$ and day of birth $(75.6$ vs $56.1 \%, P<0.05)$. However, we observed similar rates of vitrified embryos that reach day 6 and embryos that implanted $(63.1$ and $66.4 \%)$, showing no additional losses in this period. Nevertheless, after day 14 of gestation another fall in the number of foetuses that were finally born was observed ( 7.5 vs $16.8 \%$; $P<0.05)$, suggesting that alterations caused by vitrification are not completely resolved in viable implanted embryos.

\section{Foetal growth and maternal placenta are reduced in vitrified foetus in the following days after implantation}

To clarify whether second peak of losses was related with the onset of placenta formation, the foetus and the foetal and maternal placentas were weighted at day 14 of development. As it is possible to see in the Fig. 2B, there is a marked difference between the growth of control and vitrified foetus, and also in maternal placenta confirming that vitrification effects were not overcome in the middle of gestation. There was not any difference in foetal placenta weight.
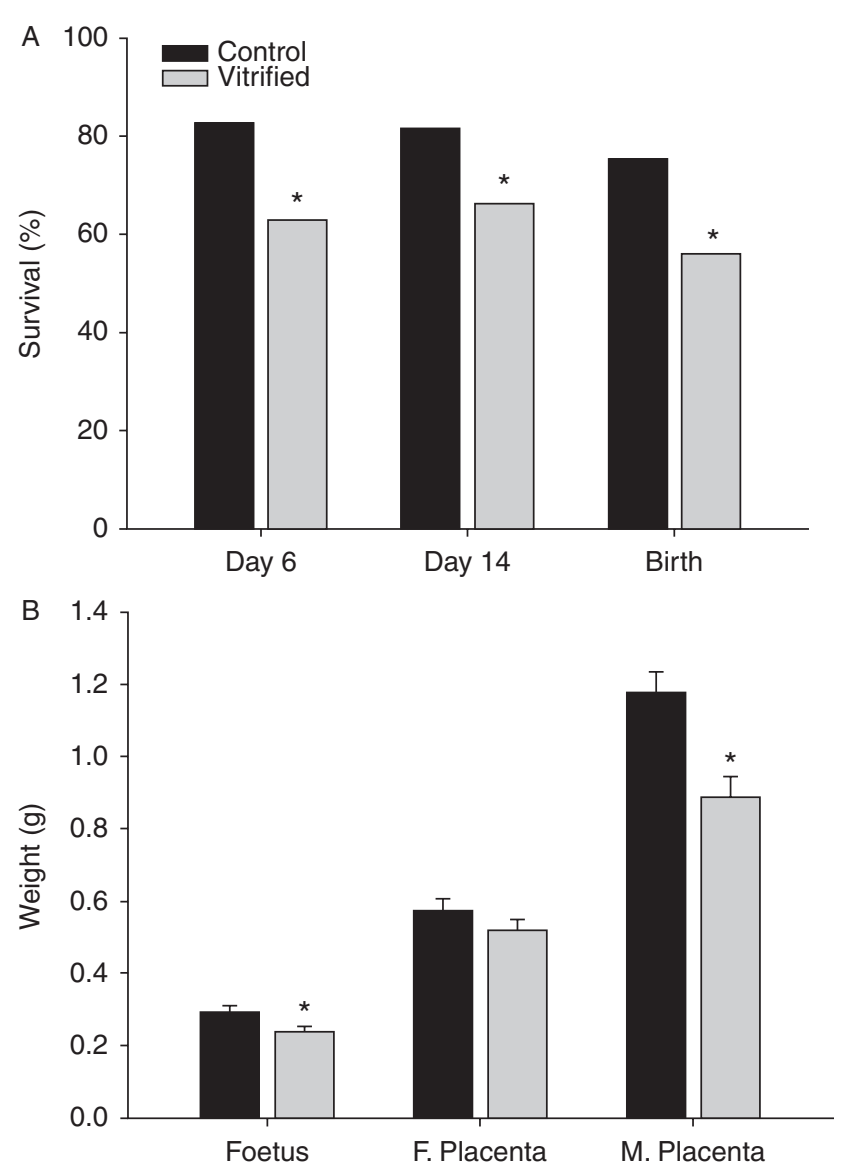

Figure 2 (A) Distribution of losses through the gestation for control and vitrified-transferred embryos. Bar charts show the mean value of the survivor percentage at days 6,14 , and at birth. (B) Foetus and foetal and maternal placental weights at day 14 . Bar charts show the mean value \pm s.E.M. Asterisk in both graphs indicates significant differences between control and vitrified transferred embryos $(P<0.05)$.

\section{The weight at birth was higher in vitrified embryos}

As a first approach to evaluate the consequences of vitrification in neonatal life, after the delivery all newborns were weighed. We observed that vitrified pups were bigger than their control counterparts $(57.2 \pm 1.12$ vs $53.4 \pm 1.32, P<0.01)$. The covariate value was 8.93 and the coefficient of the covariate was $2.47 \pm 0.319$.

\section{Vitrification process alters gene expression profile of foetal placentas (day 14), but not pre-implantatory late blastocyst transcriptome (day 6)}

Distribution of losses and low weight observed in vitrified 14-day-old foetus led us to examine the effect of vitrification in gene expression before and after implantation. For this reason, we carried out a microarray analysis to evaluate the transcriptome of pre-implantatory late blastocyst and foetal placenta. Hierarchical clustering of samples revealed that foetal 


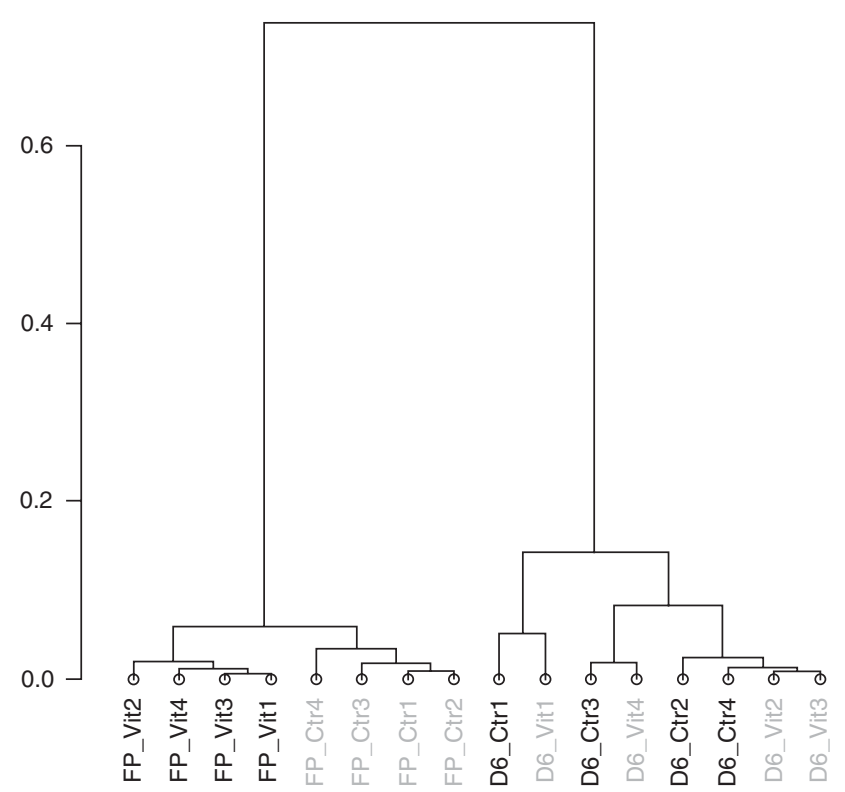

Figure 3 Hierarchical clustering of transcriptome data for 6-day-old embryos (D6) and foetal placentas (FP) for control (Crt) and vitrified (Vit) group. A Pearson correlation coefficient was used as a measure of distance between samples.

placentas samples cluster together depending on the origin of the embryo (Fig. 3). However, 6-day-old embryos did not show a clear separation between experimental groups (Fig. 3). All data related with this study have been deposited on GEO database (accession no. GSE51208). In 6-day-old embryos, limma analysis did not detected any differentially expressed gene. On the contrary, in the case of foetal placenta samples, 145 differentially expressed probes were identified, all of them upregulated in those placentas derived from vitrified embryos. Annotation of these probes revealed a total of 60 genes, and a short description and the fold change values obtained are shown in Table 2 .

\section{Upregulated genes in foetal placentas are involved in lipid metabolism, coagulation system, acute-phase response signal and intrinsic/extrinsic prothrombin activation pathway}

In order to attempt a functional annotation of overexpressed genes, the official human name of genes was submitted to DAVID database. Gene ontology (GO) terms of altered genes that were significantly overrepresented after Benjamini-Hochberg correction for multiple testing, for biological process were those for response to organic substance and wounding, chemical homeostasis, macromolecular complex subunit organisation and lipid transport, localisation and metabolism. The principal cellular components altered were extracellular region and protein-lipid complexes. As far as molecular function concerned, significant annotations were related to lipid binding, transport and serine-type peptidase and hydrolase activity. Moreover, DAVID analysis also identified as significantly altered the KEGG pathway complement and coagulation cascades, with a total of nine genes implied (FGG, F10, C9, FGB, SERPINF2, F2, F9, CFI and PROC).

IPA analysis revealed that the upregulated genes were significantly associated with the canonical pathways: LXR/RXR activation, coagulation system, acute-phase response signalling and intrinsic/extrinsic prothrombin activation pathway. IPA network interaction analysis detected three main networks. The first one showed the relationships of genes involved in protein synthesis, lipid metabolism and molecular transport (Fig. 4). In particular, 22 of the upregulated genes participated in this network. The second network generated represented genes involved in cell cycle, hepatic and haematological system development and function, and involved 17 overexpressed genes. The third one was also related with lipid metabolism, molecular transport and small molecule biochemistry and implied 11 overexpressed genes.

\section{Q-RT-PCR validated microarray results}

Microarrays results were validated by Q-RT-PCR analysis. We selected ten genes $(A F P, A P O B, A P O M$, CITED1, FABP1, LRP2, OTC, RBP4, TRF and TTR) found differentially expressed by microarray. For both microarrays (6-day-old embryos and foetal placenta at day 14), nine samples for each experimental group (control and vitrified) were used as biological replicates. In the case of embryos, Q-RT-PCR-obtained values were very similar to those obtained with the microarray analysis and again showed no significant changes in vitrified late blastocyst gene expression (Fig. 5A). In the case of foetal placentas, a significant upregulation was found in all genes, excepting in CITED1 which showed no differential expression for Q-RT-PCR experiment (with a $P$ value of 0.054) (Fig. 5B).

\section{Differential expression of serotransferrin is also observed at protein level}

To address the proteomic consequences of the changes observed in gene expression, proteins extracted from foetal placenta of control and vitrified foetus were subjected to comparative analysis by 2D-DIGE (Fig. 6A). According to the DeCyder software analysis, 30 proteins spots were found downregulated with an absolute ratio of more than 1.5 -fold, and 59 were found upregulated (Fig. 6B). Then, 27 of those upregulated spots were cut from the gels (Fig. 6A), digested and applied to LC/MS/MS analysis. We successfully identified 22 spots (Table 3), but some of the spots were identified as the same protein as in the case of albumin 
Table 2 Differentially upregulated genes in foetal placentas developed from vitrified embryos.

\begin{tabular}{|c|c|c|c|}
\hline Accession number & Gene symbol & Gene description & Fold change $^{\mathrm{a}}$ \\
\hline ENSOCUT00000003596 & $A B C B 11$ & ATP-binding cassette, sub-family B (MDR/TAP), member 11 & 2.3 \\
\hline ENSOCUT00000003596 & ACSL5 & Acyl-CoA synthetase long-chain family member 5 & 2.7 \\
\hline ENSOCUT00000016308 & $A F P$ & $\alpha$-fetoprotein & 10.2 \\
\hline ENSOCUT00000011615 & ALDH8A1 & Aldehyde dehydrogenase 8 family, member A1 & 3.5 \\
\hline ENSOCUT00000014943 & $A L D O B$ & Aldolase $\mathrm{B}$, fructose-bisphosphate & 1.7 \\
\hline ENSOCUT00000013521 & APOA2 & Apolipoprotein A-II & 7.7 \\
\hline ENSOCUT00000011230 & APOA4 & Apolipoprotein A-IV & 3.9 \\
\hline ENSOCUT00000005339 & $A P O B$ & Apolipoprotein B & 5.9 \\
\hline ENSOCUTO0000014288 & $A P O F$ & Apolipoprotein $\mathrm{F}$ & 7.1 \\
\hline ENSOCUT00000007927 & APOM & Apolipoprotein M & 7.5 \\
\hline XM_002722668 & $B T N 3 A 3$ & Butyrophilin, subfamily 3 , member A3 & 5.3 \\
\hline ENSOCUT00000012709 & C9 & Complement component 9 & 1.5 \\
\hline XM_002713434 & $\mathrm{CDH} 2$ & Cadherin 2, type $1, \mathrm{~N}$-cadherin (neuronal) & 2.8 \\
\hline XR_024370 & CEACAM1 & $\begin{array}{l}\text { Carcinoembryonic antigen-related cell adhesion molecule } 1 \\
\text { (biliary glycoprotein) }\end{array}$ & 2.3 \\
\hline XM_002804290 & CFI & Complement factor I & 3.9 \\
\hline ENSOCUT00000013306 & CITED1 & $\begin{array}{l}\text { Cbp/p300-interacting transactivator, with Glu/Asp-rich carboxy- } \\
\text { terminal domain, } 1\end{array}$ & 1.6 \\
\hline X57209 & CYP4A5 & Cytochrome P450, family 4, subfamily A & 1.6 \\
\hline ENSOCUT00000006419 & $\mathrm{DHDH}$ & Dihydrodiol dehydrogenase (dimeric) & 3.8 \\
\hline NM_001082218 & DHRS4 & Dehydrogenase/reductase (SDR family) member 4 & 1.9 \\
\hline ENSOCUT00000009647 & $D N A J B 7$ & Dnaj (Hsp40) homolog, subfamily B, member 7 & 2.2 \\
\hline ENSOCUT00000011951 & GST & Glutathione-S-Transferase & 4.2 \\
\hline ENSOCUT00000013015 & ELOVL2 & Elongation of very long-chain fatty acids like 2 & 3.1 \\
\hline XM_002713591 & ENOSF1 & Enolase superfamily member 1 & 1.4 \\
\hline XM_002720843 & ETV1 & ets variant 1 & 3.2 \\
\hline NM_-001082016 & F10 & Coagulation factor $X$ & 3.6 \\
\hline ENSOCUT00000005236 & F9 & Coagulation factor IX & 2.3 \\
\hline ENSOCUT00000016957 & $F A B P 1$ & Fatty acid-binding protein 1 , liver & 8.1 \\
\hline ENSOCUG00000010583 & $F B P 1$ & Fructose-1,6-bisphosphatase 1 & 2.5 \\
\hline ENSOCUT00000011233 & $F G B$ & Fibrinogen $\beta$ chain & 3.1 \\
\hline ENSOCUT00000011250 & $F G G$ & Fibrinogen $\gamma$ chain & 3.5 \\
\hline NM_001082083 & HMGCS1 & 3-hydroxy-3-methylglutaryl-coenzyme A synthase 1 (soluble) & 1.5 \\
\hline NM_001082760 & $H P X$ & Hemopexin & 3.1 \\
\hline ENSOCUT00000004625 & ITI-HC2 & Inter- $\alpha$ (globulin) trypsin inhibitor $\mathrm{H} 2$ & 3.0 \\
\hline ENSOCUT00000009083 & $K L B$ & Klotho $\beta$ & 1.5 \\
\hline ENSOCUT00000006194 & KYNU & Kynureninase (L-kynurenine hydrolase) & 2.1 \\
\hline ENSOCUT00000013625 & LEAP2 & Liver-expressed antimicrobial peptide 2 & 1.8 \\
\hline ENSOCUT00000002487 & $\angle G A L S 2$ & Lectin, galactoside-binding, soluble, 2 & 5.7 \\
\hline ENSOCUT00000001646 & LIPC & Lipase, hepatic & 4.6 \\
\hline ENSOCUT00000011039 & $L R P 2$ & LDL-related protein 2 & 4.3 \\
\hline ENSOCUT00000014140 & NAALAD2 & $N$-acetylated $\alpha$-linked acidic dipeptidase 2 & 2.4 \\
\hline ENSOCUT00000005730 & NOSTRIN & Nitric oxide synthase trafficker & 2.8 \\
\hline ENSOCUT00000010529 & OTC & Ornithine carbamoyltransferase & 3.9 \\
\hline ENSOCUT00000007054 & PENK & Proenkephalin & 1.7 \\
\hline ENSOCUT00000015843 & PROC & Protein C (inactivator of coagulation factors Va and VIIIa) & 3.3 \\
\hline NM_001082022 & RBOCT1 & Renal organic cation transporter & 2.5 \\
\hline ENSOCUT00000010524 & RBP4 & Retinol-binding protein 4 , plasma & 6.8 \\
\hline NM_001082003 & $R G N$ & Regucalcin (senescence marker protein-30) & 4.3 \\
\hline NM_001082741 & SERPINF2 & $\begin{array}{l}\text { Serpin peptidase inhibitor, clade } \mathrm{F} \text { ( } \alpha-2 \text { antiplasmin, pigment } \\
\text { epithelium derived factor), member } 2\end{array}$ & 2.8 \\
\hline ENSOCUT00000017509 & SERPINI1 & Serpin peptidase inhibitor, clade I (neuroserpin), member 1 & 2.3 \\
\hline NM_001082121 & SLC22A8 & Solute carrier family 22 (organic anion transporter), member 8 & 6.2 \\
\hline ENSOCUT00000016830 & SLC27A2 & Solute carrier family 27 (fatty acid transporter), member 2 & 3.1 \\
\hline ENSOCUT00000005464 & $S L C 3 A 1$ & $\begin{array}{l}\text { Solute carrier family } 3 \text { (cystine, dibasic and neutral amino acid } \\
\text { transporters, activator of cystine, dibasic and neutral amino acid } \\
\text { transport), member } 1\end{array}$ & 2.6 \\
\hline ENSOCUT00000006920 & SLC5A11 & Solute carrier family 5 (sodium/glucose cotransporter), member 11 & 2.4 \\
\hline XM_525858 & SOWAHC & Ankyrin repeat domain 57 & 1.4 \\
\hline ENSOCUT00000005024 & SULT1E1 & Sulphotransferase family $1 \mathrm{E}$, estrogen-preferring, member 1 & 3.7 \\
\hline NM_003236 & TGFA & Transforming growth factor, $\alpha$ & 1.8 \\
\hline M81396 & THROMBIN & Coagulation factor II (thrombin) & 2.2 \\
\hline ENSOCUT00000000117 & TM4SF2O & Transmembrane $4 \mathrm{~L}$ six family member 20 & 2.3 \\
\hline ENSOCUT00000007617 & TRF & Serotransferrin & 5.6 \\
\hline ENSOCUT00000017346 & $T T R$ & Transthyretin & 8.9 \\
\hline
\end{tabular}

${ }^{\mathrm{a}}$ Fold change values are on a log 2 scale. 


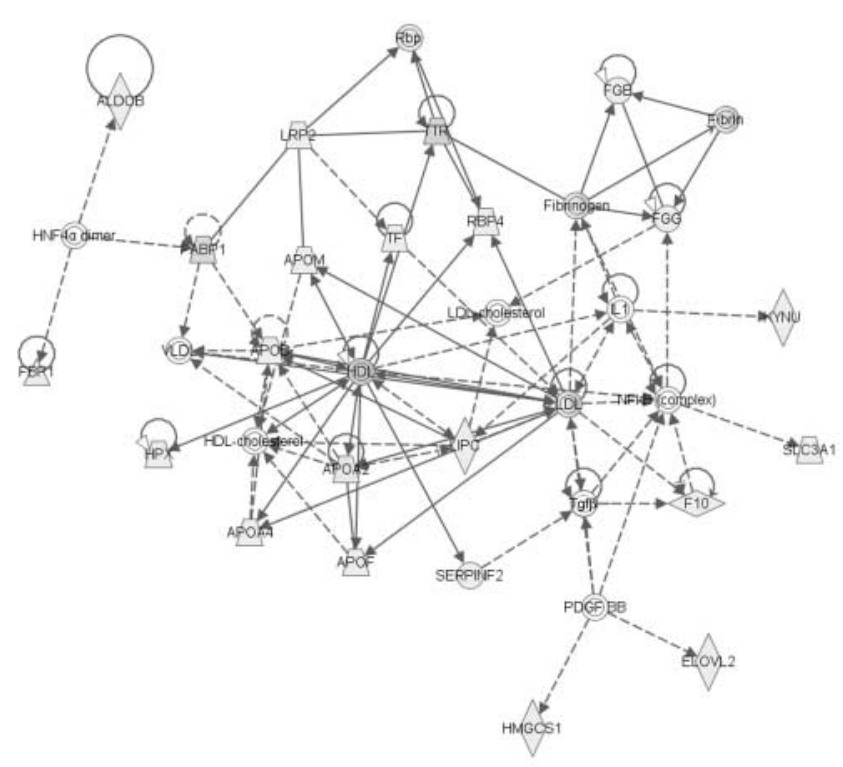

Figure 4 Graphical representations of ingenuity pathway interaction network analysis. The first top-scored network generated by IPA had a score of 48 and show relationships of genes involved in protein synthesis, lipid metabolism and molecular transport. A solid line indicated a direct interaction between nodes (genes/gene products), and a dashed line indicated an indirect relationship. The shape of the node is indicative of its function, and the colour intensity indicates fold-change level. IPA score is associated with the significance of the selected gene network. The higher the score, the more reliable it is (Betsha et al. 2013).

(ALB), $\beta$-actin (ACTB) and serotransferrin (TRF), becoming a final list of 15 different proteins. Different $\mathrm{pl}$ and molecular mass values for a unique protein might account for isoforms or post-translationally modified forms of this protein.

After functional annotation with BLAS2GO software, it was found that the most general biological processes affected were translation, protein transport, DNA metabolic process, protein modification process and cytoskeleton organisation. Figure 6 shows those specific $\mathrm{GO}$ categories for cellular component (C), biological process (D) and molecular function (E) that were represented with more than $30 \%$ of the sequences.

\section{Discussion}

There are two major findings originated from this study. First, we show that vitrification affected foetus, maternal placenta and new-born weights. Second, we have identified for the first time profound differences in the transcriptome and proteome of foetal placental of embryos that have been subjected to vitrification. Therefore, we present a strong evidence of alterations in development and placental formation of implanted cryopreserved embryos that could be implicated in gestational losses.

The strongest evidence to demonstrate the viability of embryo vitrification is to show their potential to develop to full-term offspring. Taking into account the current study with previous studies in rabbit, the two major peaks of losses during gestation of vitrified transferred embryos could be placed before the implantation (from transfer to day 6 of development) and after the implantation (from day 14 till the birth). Data results from survival at 6 and 14 days of gestation suggested no additional losses in this period for fresh and vitrified embryos $(82.7$ and $81.7 \%$ and 63.1 and $66.4 \%$ respectively). Therefore, from the transfer to the preimplantatory late blastocyst stage, a preliminary
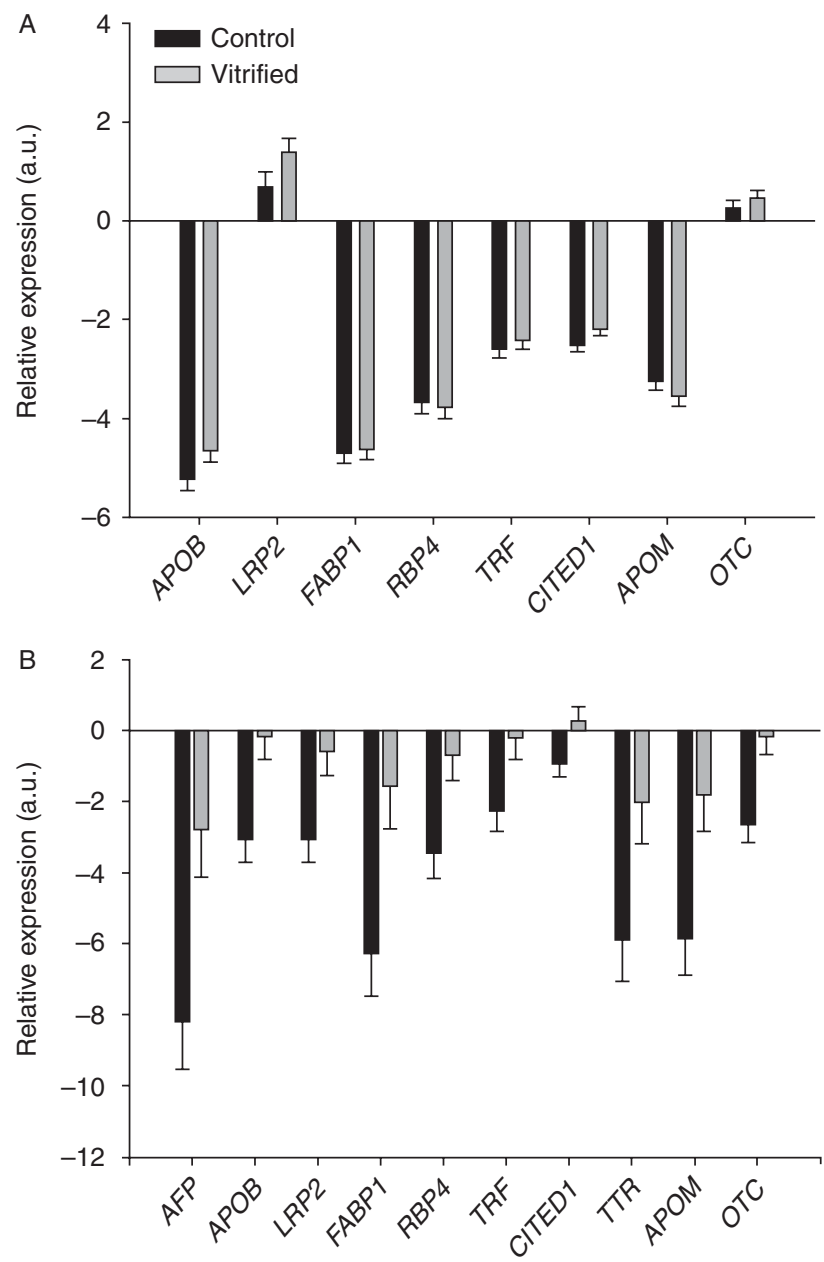

Figure 5 Quantitative real-time PCR (qPCR) analysis for selected genes for microarray validation. The expression pattern obtained for the comparison of 6-day-old control and vitrified embryos (A), and foetal placentas derived from control and vitrified embryos were consistent with microarrays results (B). Relative abundance values are expressed in arbitrary units (a.u.), showing the mean value \pm s.E.M. for nine biological replicates for each. Asterisk indicates significant differences between control and foetal placentas derived from vitrified embryos $(P<0.05)$. AFP, $\alpha$-fetoprotein; $A P O B$, apolipoprotein; $A P O M$, apolipoprotein M; CITED1, Cbp/p300-interacting transactivator, with Glu/Asp-rich carboxy-terminal domain, $1 ; F A B P 1$, fatty acid-binding protein 1; LRP2, LDL-related protein 2; OTC, ornithine carbamoyltransferase; $R B P 4$, retinol-binding protein4; TRF, serotransferrin; TTR, transthyretin. 
A

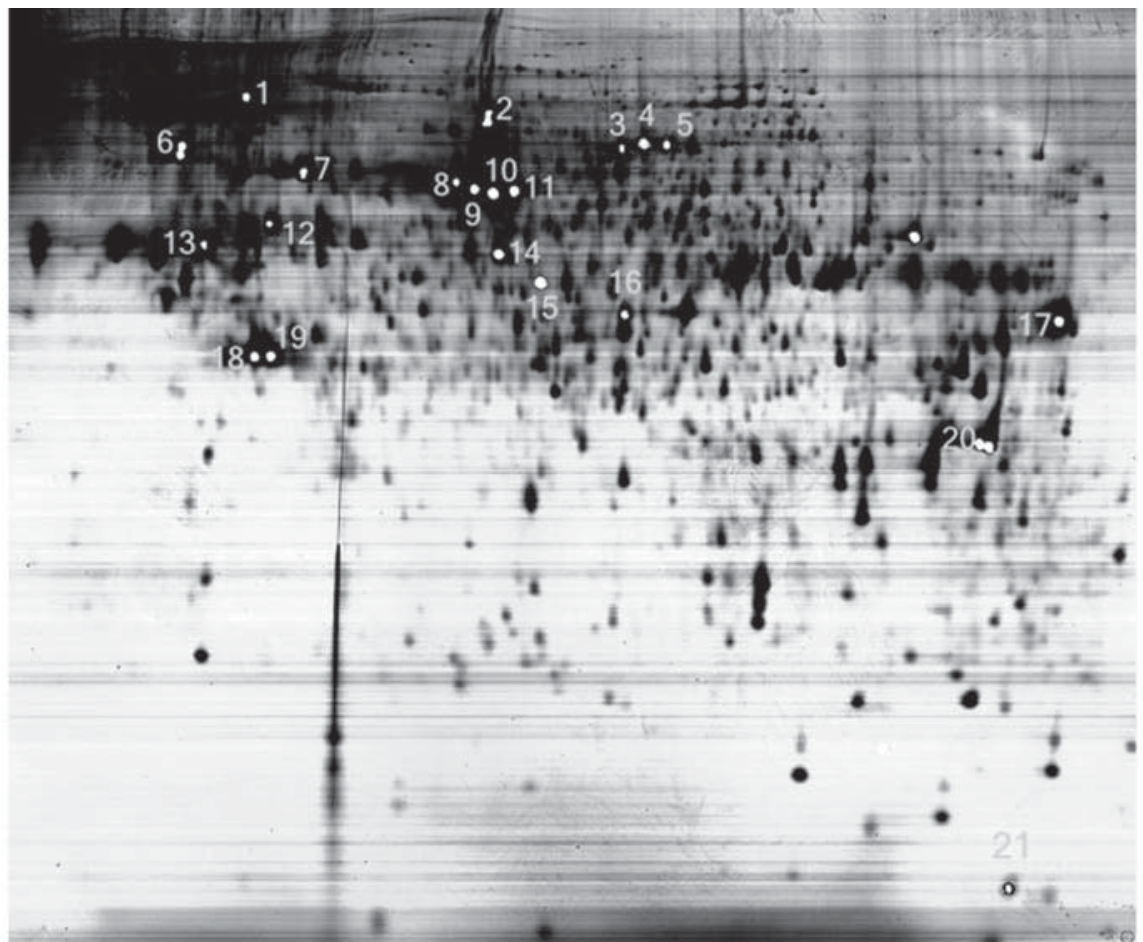

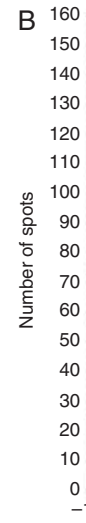

$\mathrm{D}$

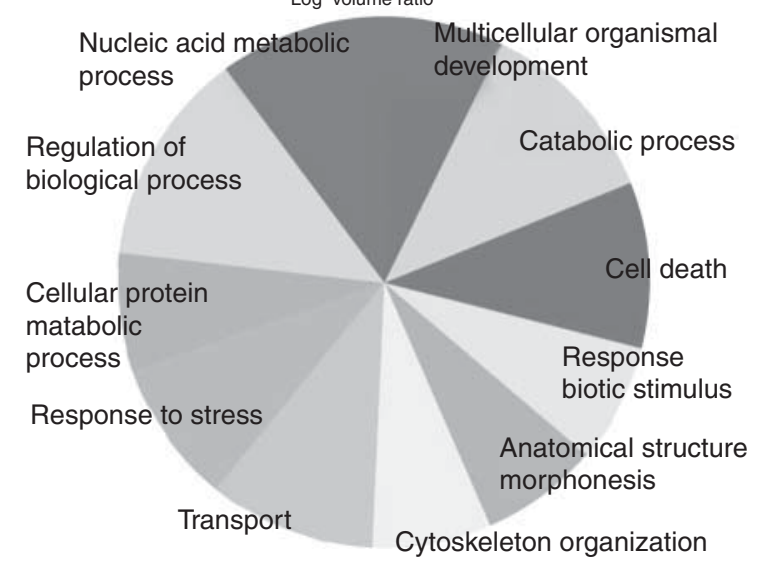

C

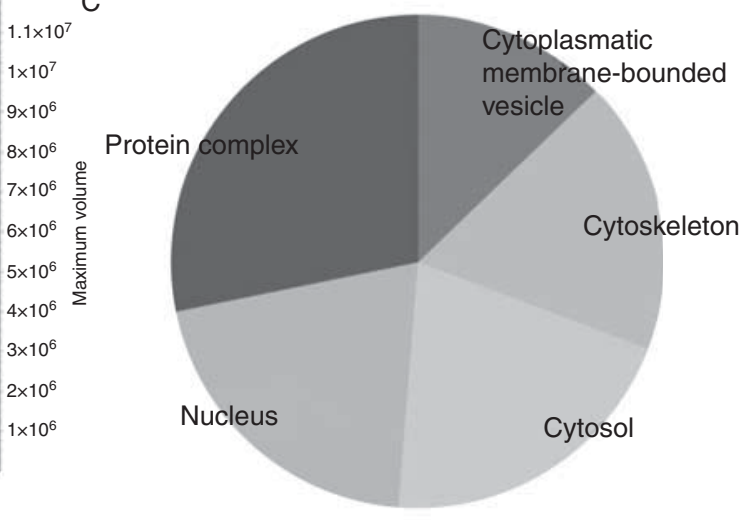

E

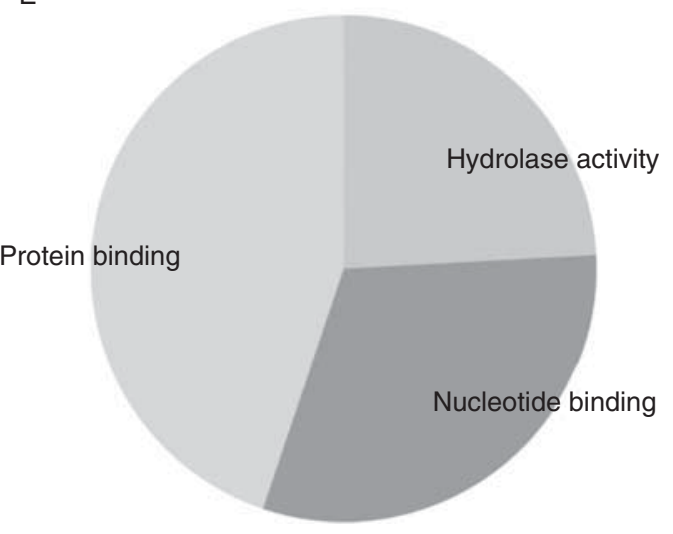

Figure 6 (A) Representation of 2D DIGE gel. Proteins picked for identification are outlined in white and the tagged numbers correspond to the same ones indicated in Table 2. (B) Volcano plot representation of spots identified by DeCye software with a fold change value higher than 1.5. Proteins induced in foetal placentas derived from vitrified embryos are located at the right side and those derived from control embryos are located in the left side of the volcano plot. Specific gene ontology (GO) categories for cellular component (C), biological process (D) and molecular function (E) that were represented with more than $30 \%$ of the sequences. 
Table 3 List of identified upregulated proteins.

\begin{tabular}{|c|c|c|c|c|c|c|c|c|}
\hline Spot no. & $\begin{array}{l}\text { Gene } \\
\text { name }\end{array}$ & Accession number & $\begin{array}{l}\text { Mol. mass } \\
\text { (theoretical) }\end{array}$ & $\begin{array}{c}\text { pl } \\
\text { (theoretical) }\end{array}$ & $\begin{array}{l}\text { Peptide } \\
\text { matched }\end{array}$ & $\begin{array}{l}\text { Mascot } \\
\text { score }\end{array}$ & $\begin{array}{c}\text { Seq. } \\
\text { cov. }(\%)\end{array}$ & Description \\
\hline 1 & $V C P$ & ENSOCUP00000005566.2 & 89322 & 4.9 & 16 & 1108 & 48 & $\begin{array}{l}\text { Valosin-containing } \\
\text { protein }\end{array}$ \\
\hline 2 & $A L B$ & ENSOCUP00000014006.2 & 68965 & 6.3 & 19 & 1290 & 37 & Serum albumin precursor \\
\hline 3 & $T R F$ & ENSOCUP00000006587.2 & 76685 & 6.8 & 9 & 621 & 14 & Serotransferrin precursor \\
\hline 4 & $T R F$ & ENSOCUP00000006587.2 & 76685 & 6.8 & 36 & 275 & 43 & Serotransferrin precursor \\
\hline 5 & $T R F$ & ENSOCUP00000006587.2 & 76685 & 6.8 & 20 & 61 & 24 & Serotransferrin precursor \\
\hline 6 & HSPA5 & ENSOCUP00000025421.1 & 72435 & 4.9 & 39 & 402 & 47 & $\begin{array}{l}\text { Heat shock } 70 \mathrm{kDa} \\
\text { protein } 5\end{array}$ \\
\hline 7 & HSPA8 & ENSOCUP00000013344.2 & 71082 & 5.2 & 26 & 190 & 37 & $\begin{array}{l}\text { Heat shock } 70 \mathrm{kDa} \\
\text { protein } 8\end{array}$ \\
\hline 8 & $A L B$ & ENSOCUP00000014006.2 & 68965 & 6.3 & 17 & 1046 & 27 & Serum albumin precursor \\
\hline 9 & $A L B$ & ENSOCUP00000014006.2 & 68965 & 6.3 & 48 & 2072 & 55 & Serum albumin precursor \\
\hline 10 & $A L B$ & ENSOCUP00000014006.2 & 68965 & 6.3 & 306 & 5515 & 88 & Serum albumin precursor \\
\hline 11 & $A L B$ & ENSOCUP00000014006.2 & 68965 & 6.3 & 29 & 1074 & 46 & Serum albumin precursor \\
\hline 12 & HSPD1 & ENSOCUP00000010958.2 & 61170 & 5.4 & 8 & 646 & 18 & Heat shock protein 65 \\
\hline 13 & TUBA1B & ENSOCUP00000003531.2 & 50182 & 4.6 & 12 & 726 & 32 & $\alpha$-tubulin \\
\hline 14 & PDIA3 & ENSOCUP00000001003.2 & 56562 & 6.3 & 28 & 1692 & 50 & $\begin{array}{l}\text { Protein disuphide-isomer- } \\
\text { ase A3 precursor }\end{array}$ \\
\hline 15 & TUBB1 & ENSOCUP00000013717.2 & 50063 & 4.7 & 88 & 841 & 50 & Tubulin $\beta$-like \\
\hline 16 & ENO1 & ENSOCUP00000008689.2 & 47273 & 7.1 & 16 & 1244 & 43 & Enolase-1-like \\
\hline 17 & EE1A1 & ENSOCUP00000007327.2 & 50141 & 9.4 & 4 & 315 & 13 & Elongation factor $1 \propto 1$ \\
\hline 18 & $A C T B$ & ENSOCUP00000005083.2 & 40484 & 5.9 & 13 & 96 & 30 & Actin cytoplasmatic 1 \\
\hline 19 & $A C T B$ & ENSOCUP00000005083.2 & 40484 & 5.9 & 55 & 1572 & 63 & Actin cytoplasmatic 1 \\
\hline 20 & GAPDH & ENSOCUP00000022125.1 & 35835 & 8.6 & 8 & 624 & 37 & $\begin{array}{l}\text { Glyceraldehyde-3-phos- } \\
\text { phate dehydrogenase }\end{array}$ \\
\hline 21 & $H B B$ & ENSOCUP00000000491.2 & 16142 & 8.5 & 14 & 171 & 67 & $\begin{array}{l}\text { Haemoglobin subunit } \\
\text { beta }\end{array}$ \\
\hline 22 & PFN1 & ENSOCUP00000000960.2 & 10607 & 9.7 & 84 & 328 & 40 & Profilin-1-like \\
\hline
\end{tabular}

selection of embryos might be carried out in the maternal tract and only those embryos that were able to overcome vitrification were able to develop and begin implantation and placentation process. Nevertheless, after day 14 of gestation, a significant fall in the number of foetuses that were finally born was observed $(7.5 \%$ vs $16.8 \%$, for fresh and vitrified embryos respectively), suggesting that alterations caused by vitrification were still present in implanted embryos. Results agree with previous observations made by other authors (Mocé et al. 2010, Marco-Jiménez et al. 2013, Vicente et al. 2013), who detected a second peak of foetal mortality between 14 and 25 days and problems in formation of the placenta.

Up to now few reports, and only in mouse and bovine species, have analysed the effect of vitrification on whole embryo transcriptome before the onset of implantation (Mamo et al. 2006, Larman et al. 2011, Aksu et al. 2012), and none of them analysed what happen with those embryos that get implanted and follow with the gestation. Moreover, in contrast to our research, all these published works were carried out under in vitro culture to select viable vitrified embryos, even though it is known that in vitro culture systems do not mimic the uterine environment, and gene expression of embryos that developed in vitro differ from their in vivo counterparts (Corcoran et al. 2006). For these reasons, to carry out our experiment, we used an in vivo model, and we transferred the vitrified embryo to a receptive female and gave them the best environment for their development till day 6 or 14. In this way, we analysed also the effects of a complete cryopreservation procedure, which involves several embryo manipulations such as in vitro handling, washings or transfer to another maternal tract. Our results showed that despite fresh and vitrified embryos had different ability to reach late blastocyst stage, when both groups achieve the end of pre-implantatory development they did not present transcriptomic divergences. These results were similar to those observed by Larman et al. (2011), in which vitrified mouse blastocyst showed the same transcriptomic pattern as fresh group after $6 \mathrm{~h}$ of in vitro culture. Furthermore, these findings were according to our developmental results, and could explain why vitrified embryos that reached day 6 were also able to implant.

As stated before, previous observations in vitrified rabbit embryos detected problems in the formation of the placenta (Mocé et al. 2010, Marco-Jiménez et al. 2013, Vicente et al. 2013), suggesting that the causes of this mortality observed during the second part of gestation were probably orchestrated in the period comprised between the initiation of implantation and placental development (6-14 days of gestation in rabbit). The placenta is the transient organ that mediates nutrients and gas exchange between the mother and the developing embryo or foetus (Yllera et al. 2003). It replaces the functions of the foetal lung, gut, liver, and kidney and as a multipotential organ, it also performs actions of the ovary, pituitary, and hypothalamus. 
Although the morphology of placenta varies considerably between mammals, the main function remains common and the establishment of a healthy and functional placenta is a crucial element in embryonic and foetal development (Yllera et al. 2003). Our findings provide the first evidence, to our knowledge, of a lower weight in foetus ( $\sim 24 \%)$ and maternal placenta $(\sim 46 \%)$ at day 14 in vitrified group. These were according to previous results observed by ultrasonography by Vicente et al. (2013). In rabbit, definitive mesometrial chorioallantoid placentation occurs at day 8 with the establishment of embryo-maternal exchange, controlled by temporal and local signals (Fischer et al. 2012). Thus, the decrease in foetus and maternal placenta weight could be a consequence of disruption in the molecules involved in this embryo-maternal dialogue. Because the foetal placenta is the organ in physical contact with maternal placenta and foetus, we carried out a transcriptomic and proteomic analyses of this tissue. Then, we detected in the vitrified group 60 differentially expressed genes, all of them upregulated, and 89 differentially expressed protein spots (59 upregulated and 30 downregulated). Identified genes were involved in the response to organic substance and wounding, chemical homeostasis, macromolecular complex subunit organisation, and lipid transport, localisation and metabolism. On the other hand, identified proteins were involved in molecular functions such as translation, protein transport, DNA metabolic process, protein modification process and cytoskeleton organisation.

Focusing on mRNA expression, we observed several genes belonging to the complement and coagulation KEGG pathway (FGG, F10, C9, FGB, SERPINF2, F2, F9, $\mathrm{CFI}$ and $\mathrm{PROC}$ ). So, an imbalance in any molecule of this complement or fibrinolytic system could lead to placental dysfunction and problems in the maintenance of normal haemostasis and the placental blood circulation (Salmon et al. 2011, Xin et al. 2012). The most significant altered gene was Alfa-fetoprotein $(A F P)$, a major foetal plasma protein produced by the yolk sac and the liver. This glycoprotein is widely used as a maternal serum protein biomarker of Down syndrome and adverse perinatal outcome (Pennings et al. 2009, Allen et al. 2013). However, we observed the mRNA expression of this gene in the foetal placenta, indicating that this tissue could also contribute to the elevated levels commonly associated with developmental foetus alterations.

We also identified one gene that was upregulated at mRNA and protein level in foetal placentas derived from vitrified embryos. The serotransferrin gene (TRF), encode a circulating serum protein responsible for iron transport from tissue sites of absorption to sites of storage or utilisation, and is considered also a stimulator of cell proliferation (Mason et al. 2012). It has been observed that increased expression of TRF in human placenta from pregnancies of selected abnormalities may indicate an increased need of foetal iron supplies, which could lead in a foetal stress and cause serious effects such as foetal growth retardation and cardiovascular problems in the adult offspring (Kralova et al. 2008). Likewise, in in vitrocultured mouse embryos, it was observed a misregulation of serotransferrin induced by alcohol exposure during its development (Mason et al. 2012). Focusing on the other fourteen identified proteins, it is important to highlight that we found proteins previously identified in human placenta such as haemoglobin $\beta$, tubulin, transitional endoplasmatic reticulum ATPase or serotransferrin. We also observed an upregulation of other proteins previously related to placental dysfunction (preeclampsia and pre-term labour), such as serum albumin precursor, $\beta$-actin, $\alpha$ enolase, protein disulphideisomerase precursor or heat shocks proteins (Mushahary et al. 2013).

In rabbit, after fertilisation the early development events are regulated by maternal RNAs and proteins synthesised during oogenesis, and the embryonic nuclei become transcriptionally active only when the maternal-embryonic transition occurs at 8-cell stage (Manes 1973, Christians et al. 1994, Léandri et al. 2009). Despite this autonomous development, it is well known that pre-implantatory mammalian embryos are sensitive to environmental conditions in which they develop (Fleming et al. 2004, Duranthon et al. 2008). During the cryopreservation and transfer procedures, preimplantatory embryos experience different hostile environments: washes, exposure to cryoprotectant medium, cooling and warming.

As Whittingham \& Anderson (1976) suggested, these processes could induce a delay in the restoration of normal metabolic and synthetic activities. This lag in the resumption of development might explain the low growth of vitrified foetuses at day 14 and the differences in placenta expression of genes related with protein synthesis, lipid metabolism and molecular transport. Recently, Chatzimeletiou et al. (2012) observed that after vitrification there were more abnormal spindles in the trophectoderm cells than in the inner cell mass. This difference in the location of the abnormal spindles could also explain why the placenta, derived from trophectoderm, was altered at day 14 .

It has been reported that the embryonic ability to adapt to sub-optimal conditions and stressful environmental experiences could contribute to the foetal programming of developmental plasticity and/or enhance adjustment to the postnatal environment (Pluess \& Belsky 2011). The 'foetal origins hypothesis' postulates that a number of organ structures and associated functions undergo programming during embryonic, foetal life and neonatal period, which determines the set point of physiological and metabolic responses that carry into adulthood (Lau \& Rogers 2004, McMillen et al. 2004, Langley-Evans et al. 2005). A 'memory' of the injury could be stored in 
the developing embryo, mainly by the presence of epigenetic marks. Other studies have supported in other mammalian species that vitrification change epigenetic patterns of developing embryos (Wang et al. 2010, Zhao et al. 2012). Particularly in rabbit, Reis e Silva et al. (2012) observed that DNA demethylation kinetics of early pre-implantatory development was influenced by in vitro culture. Actually, it is accepted that epigenetic alteration induced by environmental factors can be inherited across generations in mammals despite extensive reprogramming both in the gametes and in the earlydeveloping embryo (Anway et al. 2005, Daxinger \& Whitelaw 2012). So, taking into account that vitrified new-borns weighed more than the control ones, the question arises as to whether this is the only effect in neonatal life or will they have more consequences in the adulthood. Therefore, more studies should focus on epigenetic alterations of vitrification and long-term consequences.

In conclusion, our observations appear relevant to the growing evidence that embryo vitrification affected foetus, maternal placenta and new-born weights. Transcriptomic and proteomic analyses of foetal placenta suggested that the mortality observed at the second part of gestation was probably orchestrated in the period comprised between the initiation of implantation and placental formation. However, if vitrification technique is going to become a common practice in human-assisted reproduction and embryo storage, additional experiments should be made to define the factors involved in these post-implantatory losses, and to elucidate which effects could have not only in the embryo and foetal physiology but also in the neonatal and adult life.

\section{Declaration of interest}

The authors declare that there is no conflict of interest that could be perceived as prejudicing the impartiality of the research reported.

\section{Funding}

This work was supported by the Generalitat Valenciana research program (Prometeo 2009/125) and the Spanish Research Projects (CICYT AGL2011-29831-C03-01). M D Saenz-de-Juano was supported by a research grant from Generalitat Valenciana (Programa VALI+d, ACIF/2011/254).

\section{Author contribution statement}

The author(s) have made the following declarations about their contributions: conceived and designed the experiments: M D Saenz-de-Juano, F Marco-Jimenez and J S Vicente. Performed the experiments: M D Saenz-de-Juano, F Marco-Jimenez, B Schmaltz-Panneau, E Jimenez-Trigos, M P Viudesde-Castro, D S Peñaranda, L Jouneau, J Lecardonnel, R Lavara, C Naturil-Alfonso, V Duranthon and J S Vicente. Analysed the data: M D Saenz-de-Juano, B Schmaltz-Panneau, L Jouneau, F Marco-Jimenez and J S Vicente. Wrote the paper: M D Saenzde-Juano, F Marco-Jimenez, M P Viudes-de-Castro, V Duranthon and J S Vicente.

\section{Acknowledgements}

The authors thank European Cooperation in Science and Technology (COST) Action (Rabbit Genome Biology (RGB)Net no. TD1101) and Neil Macowan Language Services for revising the English version of the manuscript.

\section{References}

Aksu DA, Agca C, Aksu S, Bagis H, Akkoc T, Caputcu AT, Arat S, Taskin AC, Kizil SH, Karasahin T et al. 2012 Gene expression profiles of vitrified in vitro- and in vivo-derived bovine blastocysts. Molecular Reproduction and Development 79 613-625. (doi:10.1002/mrd.22068)

Allen R, Marleen S, Velauther L, Harrington K \& Aquilina J 2013 The relationship between second trimester alpha fetoprotein levels and adverse pregnancy outcome. Open Journal of Obstetrics and Gynecology 3 262-266. (doi:10.4236/ojog.2013.32049)

Anway MD, Cupp AS, Uzumcu M \& Skinner MK 2005 Epigenetic transgenerational actions of endocrine disruptors and male fertility. Science 308 1466-1469. (doi:10.1126/science.1108190)

Arav A 2014 Cryopreservation of oocytes and embryos. Theriogenology 81 96-102. (doi:10.1016/j.theriogenology.2013.09.011)

Auroux M, Cerutti I, Ducot B \& Loeuillet A 2004 Is embryocryopreservation really neutral? A new long-term effect of embryo freezing in mice: protection of adults from induced cancer according to strain and sex. Reproductive Toxicology 6 813-816.

Besenfelder U \& Brem G 1993 Laparoscopic embryo transfer in rabbits. Journal of Reproduction and Fertility 99 53-56. (doi:10.1530/jrf.0. 0990053)

Betsha S, Hoelker M, Salilew-Wondim D, Held E, Rings F, GrosseBrinkhause C, Cinar MU, Havlicek V, Besenfelder U, Tholen E et al. 2013 Transcriptome profile of bovine elongated conceptus obtained from SCNT and IVP pregnancies. Molecular Reproduction and Development 80 315-333. (doi:10.1002/mrd.22165)

BOE 2013 Official Spanish State Gazette, Decree 53/2013.

Chatzimeletiou K, Morrison EE, Panagiotidis Y, Vanderzwalmen $P$, Prapas N, Prapas Y, Tarlatzis BC \& Handyside AH 2012 Cytoskeletal analysis of human blastocysts by confocal laser scanning microscopy following vitrification. Human Reproduction 27 106-113. (doi:10.1093/ humrep/der344)

Christians E, Rao VH \& Renard JP 1994 Sequential acquisition of transcriptional control during early embryonic development in the rabbit. Developmental Biology 164 160-172. (doi:10.1006/dbio.1994. 1188)

Corcoran D, Fair T, Park S, Rizos D, Patel OV, Smith GW, Coussens PM, Ireland JJ, Boland MP, Evans AC et al. 2006 Suppressed expression of genes involved in transcription and translation in in vitro compared with in vivo cultured bovine embryos. Reproduction 131 651-660. (doi:10. 1530/rep.1.01015)

Daxinger L \& Whitelaw E 2012 Understanding transgenerational epigenetic inheritance via the gametes in mammals. Nature Reviews Genetics 13 153-162. (doi:10.1038/nrm3288)

Desai NN, Goldberg JM, Austin C \& Falcone T 2013 The new Rapid-i carrier is an effective system for human embryo vitrification at both the blastocyst and cleavage stage. Reproductive Biology and Endocrinology 11 41. (doi:10.1186/1477-7827-11-41)

Duranthon V, Watson AJ \& Lonergan P 2008 Preimplantation embryo programming: transcription, epigenetics, and culture environment. Reproduction 135 141-150. (doi:10.1530/REP-07-0324)

Fischer B, Chavatte-Palmer P, Viebahn C, Navarrete Santos A \& Duranthon V 2012 Rabbit as a reproductive model for human health. Reproduction 144 1-10. (doi:10.1530/REP-12-0091) 
Fleming TP, Kwong WY, Porter R, Ursell E, Fesenko I, Wilkins A, Miller DJ, Watkins AJ \& Eckert JJ 2004 The embryo and its future. Biology of Reproduction 71 1046-1054. (doi:10.1095/biolreprod.104.030957)

García-Cavazos R, Colín-Valenzuela A \& Espino y Sosa S 2010 $\alpha$-Fetoprotein as an early predictor of adverse perinatal outcome. Ginecología y obstetricia de México 78 268-274.

Kralova A, Svetlikova M, Madar J, Ulcova-Gallova Z, Bukovsky A \& Peknicova J 2008 Differential transferrin expression in placentae from normal and abnormal pregnancies: a pilot study. Reproductive Biology and Endocrinology 6 27. (doi:10.1186/1477-7827-6-27)

Langley-Evans SC, Bellinger L \& McMullen S 2005 Animal models of programming: early life influences on appetite and feeding behaviour. Maternal \& Child Nutrition 1 142-148. (doi:10.1111/j.1740-8709.2005. 00015.x)

Larman MG, Katz-Jaffe MG, McCallie B, Filipovits JA \& Gardner DK 2011 Analysis of global gene expression following mouse blastocyst cryopreservation. Human Reproduction 26 2672-2680. (doi:10.1093/ humrep/der238)

Lau C \& Rogers JM 2004 Embryonic and fetal programming of physiological disorders in adulthood. Birth Defects Research. Part C, Embryo Today 72 300-312. (doi:10.1002/bdrc.20029)

Léandri RD, Archilla C, Bui LC, Peynot N, Liu Z, Cabau C, Chastellier A, Renard JP \& Duranthon V 2009 Revealing the dynamics of gene expression during embryonic genome activation and first differentiation in the rabbit embryo with a dedicated array screening. Physiological Genomics 36 98-113. (doi:10.1152/physiolgenomics.90310.2008)

Mamo S, Bodo S, Kobolak J, Polgar Z, Tolgyesi G \& Dinnyes A 2006 Gene expression profiles of vitrified in vivo derived 8-cell stage mouse embryos detected by high density oligonucleotide microarrays. Molecular Reproduction and Development 73 1380-1392. (doi:10.1002/mrd. 20588)

Mamo S, Gal AB, Polgar Z \& Dinnyes A 2008 Expression profiles of the pluripotency marker gene POU5f1 and validation of reference genes in rabbit oocytes and preimplantation stage embryos. BMC Molecular Biology 9 67. (doi:10.1186/1471-2199-9-67)

Manes C 1973 The participation of the embryonic genome during early cleavage in the rabbit. Developmental Biology 32 453-459. (doi:10. 1016/0012-1606(73)90254-6)

Marco-Jiménez F, Lavara R, Jiménez-Trigos E \& Vicente JS 2013 In vivo development of vitrified rabbit embryos: effects of vitrification device, recipient genotype, and asynchrony. Theriogenology 79 1124-1129. (doi:10.1016/j.theriogenology.2013.02.008)

Mason S, Anthony B, Lai X, Ringham HN, Wang M, Witzmann FA, You JS \& Zhou FC 2012 Ethanol exposure alters protein expression in a mouse model of fetal alcohol spectrum disorders. International Journal of Proteomics 2012 10. (doi:10.1155/2012/867141)

McMillen IC, Muhlhausler BS, Duffield JA \& Yuen BSJ 2004 Prenatal programming of postnatal obesity: fetal nutrition and the regulation of leptin synthesis and secretion before birth. Proceedings of the Nutrition Society 63 405-412. (doi:10.1079/PNS2004370)

Mocé M, Blasco A \& Santacreu M 2010 In vivo development of vitrified rabbit embryos: effects on prenatal survival and placental development. Theriogenology 73 704-710. (doi:10.1016/j.theriogenology.2009.11. 010)

Muñoz-Fambuena N, Mesejo C, Agustí M, Tárraga S, Iglesias DJ, Primo-Millo E \& González-Mas MC 2013 Proteomic analysis of "Moncada" mandarin leaves with contrasting fruit load. Plant Physiology and Biochemistry 62 95-106. (doi:10.1016/j.plaphy.2012.10.020)

Mushahary D, Gautam P, Sundaram CS \& Sirdeshmukh R 2013 Expanded protein expression profile of human placenta using two-dimensional gel electrophoresis. Placenta 34 193-196. (doi:10.1016/j.placenta.2012.11. 015)

Navarrete-Santos A, Ramin N, Tonack S \& Fischer B 2008 Cell lineage-specific signalling of insulin and insulin-like growth factor I in rabbit blastocysts. Endocrinology 149 515-524. (doi:10.1210/en.20070821)
Pennings JL, Koster MP, Rodenburg W, Schielen PC \& de Vries A 2009 Discovery of novel serum biomarkers for prenatal Down syndrome screening by integrative data mining. PLOS ONE 4 e8010. (doi:10.1371/ journal.pone.0008010)

Pluess M \& Belsky J 2011 Prenatal programming of postnatal plasticity? Development and Psychopathology 23 29-38. (doi:10.1017) S0954579410000623)

Rall W \& Fahy G 1985 Ice-free cryopreservation of mouse embryos at $-196{ }^{\circ} \mathrm{C}$ by vitrification. Nature 313 573-575. (doi:10.1038/313573a0)

Reis e Silva AR, Bruno C, Fleurot R, Daniel N, Archilla C, Peynot N, Lucci CM, Beaujean N \& Duranthon V 2012 Alteration of DNA demethylation dynamics by in vitro culture conditions in rabbit pre-implantation embryos. Epigenetics 7 440-446. (doi:10.4161/epi. 19563)

Salmon JE, Heuser C, Triebwasser M, Liszewski MK, Kavanagh D, Roumenina L, Branch DW, Goodship T, Fremeaux-Bacchi V \& Atkinson JP 2011 Mutations in complement regulatory proteins predispose to preeclampsia: a genetic analysis of the PROMISSE cohort. PLoS Medicine 8 e1001013. (doi:10.1371/journal.pmed.1001013)

Saragusty J \& Arav A 2011 Current progress in oocyte and embryo cryopreservation by slow freezing and vitrification. Reproduction $\mathbf{1 4 1}$ 1-19. (doi:10.1530/REP-10-0236)

Shevchenko A, Jensen ON, Podtelejnikov AV, Sagliocco F, Wilm M, Vorm O, Mortensen P, Boucherie H \& Mann M 1996 Linking genome and proteome by mass spectrometry: large-scale identification of yeast proteins from two dimensional gels. PNAS 93 14440-14445. (doi:10. 1073/pnas.93.25.14440)

Vicente JS, Viudes-de-Castro MP \& García ML 1999 In vivo survival rate of rabbit morulae after vitrification in a medium without serum protein. Reproduction, Nutrition, Development 39 657-662. (doi:10.1051/ rnd:19990511)

Vicente JS, Saenz-de-Juano MD, Jiménez-Trigos E, Viudes-de-Castro MP, Peñaranda DS \& Marco-Jiménez F 2013 Rabbit morula vitrification reduces early foetal growth and increases losses throughout gestation. Cryobiology 67 321-326.

Wang Z, Xu L \& He F 2010 Embryo vitrification affects the methylation of the $\mathrm{H} 19$ /lgf2 differentially methylated domain and the expression of $\mathrm{H} 19$ and Igf2. Fertility and Sterility 93 2729-2733. (doi:10.1016/j.fertnstert. 2010.03.025)

Weltzien FA, Pasqualinib C, Vernierb P \& Dufoura S 2005 A quantitative real-time RT-PCR assay for European eel tyrosine hydroxylase. General and Comparative Endocrinology 142 134-142. (doi:10.1016/j.ygcen. 2004.12.019)

Whittingham DG \& Anderson E 1976 Ultrastructural studies of frozenthawed 8-cell mouse embryos. Journal of Reproduction and Fertility $\mathbf{4 8}$ 137-140. (doi:10.1530/jrf.0.0480137)

Xin H, Zhang Y, Wang H \& Sun S 2012 Alterations of profibrinolytic receptor annexin A2 in pre-eclampsia: a possible role in placental thrombin formation. Thrombosis Research 129 563-567. (doi:10.1016/ j.thromres.2011.07.039)

Yllera M, Alexandre-Pires GM \& Cifuentes JM 2003 Placenta: regularization of neovascularization. Microvascularization pattern of the rabbit term placenta. Microscopy Research and Technique 60 38-45. (doi:10. 1002/jemt.10241)

Zhao XM, Du WH, Hao HS, Wang D, Qin T, Liu Y \& Zhu HB 2012 Effect of vitrification on promoter methylation and the expression of pluripotency and differentiation genes in mouse blastocysts. Molecular Reproduction and Development 79 445-450. (doi:10.1002/mrd.22052)

Received 13 January 2014

First decision 3 February 2014

Revised manuscript received 11 February 2014

Accepted 17 February 2014 